\title{
REASONABLE SAMPLING SCALE OF MACROPORE BASED ON GEOSTATISTIC THEORY
}

Mingyao Zhou ${ }^{1,2, *}$, Zhaodi Lin ${ }^{2}$, Peng Wu ${ }^{2}$, Susheng Wang ${ }^{2}$,Fei Zhang ${ }^{2}$

${ }^{I}$ State Key Laboratory of Hydrology - Water Resources and Hydraulic Engineering, Hohai University, Nanjing, Jiangsu Province, P. R. China 210098

${ }^{2}$ College of Hydraulic Science and Engineering, Yangzhou University, Yangzhou, Jiangsu Province, P. R. China 225009

* Corresponding author, Address: College of Hydraulic Science and Engineering, Yangzhou University, 31 middle Jiangyang Rord, Yangzhou 225009, Jiangsu Province, P. R. China, Tel: +86-514-87978640, Fax: +86-514-87978640,Email: myzhouyz@163.com

Abstract: Spatial scale of soil character is forefront in soil-scientific research, and the analysis of macropore reasonable sampling size becomes significant in studyinig on soil spatial variability. From the micro-structure of the soil, using digital image preparation and analysis technology, this paper described the soil macropore with rations, discussed the spatial structure of soil macropore on both the vertical and horizontal directions by geologic geostatistic theory, analysed by the base value of variation function $\mathrm{C} 0$, structure variance $\mathrm{C}$, variable function, model test parameter I and model accuracy rate of change $\mathrm{k}$ and so on. The results showed that the reasonable sampling interval of vertical depth was $20 \mathrm{~mm}$, and the economic reasonable sampling diameter on horizontal was about $90 \sim 100 \mathrm{~mm}$. The production has very important significance to ensuring the scientific of the soil macropore research, saving study time, and reducing the human and financial resources in the trial.

Keywords: digital image; soil macropore degree; geostatistic theory; scale sample

\section{INTRODUCTION}

Soil is a kind of uneven and variational continuum, its spatial scale problem is in the forefront of soil-scientific research. In the pedology,

Please use the following format when citing this chapter:

Zhou, M., Lin, Z., Wu, P., Wang, S. and Zhang, F., 2009, in IFIP International Federation for Information Processing, Volume 294, Computer and Computing Technologies in Agriculture II, Volume 2, eds. D. Li, Z. Chunjiang, (Boston: Springer), pp. 1443-1450. 
configuration and variability of many regional variables usually exist in different scales, some structure just show under fixed observational measure, meanwhile, some observational measure just reveal relevant change rule or structural characteristic, the effect of spatial variability differs during different scales (Li Zizhong et at., 2001). Sampling is the first step in all macropore research, its scale effect can directly impact spatial variability rule of soil.

Geostatistical theory is a risingly fringe subject founded and developed in lately thirty years (Hou Jingru et at., 1982; Wang Renduo et at.,1988). Since it was taken into the spatial analysis of soil characteristic, geostatistical theory had largely applied to many fields, such as soil-water science, hydrology, and so on (Li Weiping et at., 2004; Shi Haibin et at.,1994).However, this theory was almostly used to study some characteristic and crop information in field scale presently. The depth of research was stressly about the spatial insert number and related interval of some soil characteristic and crop information, then drew isoline figure. Practical research showed that, in order to reflect macropore distributing in soil completely, the research of macropore spatial variability in both microcosmic and macrocosmic had become a necessarily solving problem, as the gradual development of macropore research.

Optimal sampling scale means mortal sampling scope very tittle sampling interval and sampling volume (Westerna A W et at., 1999), but in fact, this is very difficult to achieve. This paper took geostatistical theory into microcosmic domain to research macropore distributing, analysis the spatial structural characteristic, obtain the reasonable sampling size of macropore study, accurately obtain macropore distributing rule, provide instruction for soil moisture, solute movement regulation and setting up exact predictive model for cropland moisture.

\section{GEOSTATISTICAL THEORY}

Geostatistical theory is based on regional variables r random function and balanced supposes, consider semi-variance function as its basic tool, studies the natural phenomena that both randomicity and configuration in the spatial distributing (Hou Jingru et at., 1993). Semi-variation function is the core during calculating regional variables, usually take following formula which Matheron commended:

$$
\gamma(h)=\frac{1}{2 N(h)} \sum_{i=1}^{N(h)}\left[Z\left(x_{i}\right)-Z\left(x_{i}+h\right)\right]^{2}
$$


Theory

where $N(h)$ is experimentation logarithm at a distance of $\mathrm{h}$ on $x$ axis; $h$ is sampling interval; $\gamma(h)$ is the result of semi-variation function; $Z\left(x_{i}\right)$, $Z(x+h)$ is realization of observation value $Z(x), Z(x+h)$.

\section{MATERIAL AND METHOD OF EXPERIMENT}

\subsection{Prepare and dispose the soil column}

The experiment took original soil as object, and the fetching soil containers included two kinds of UPVC pipe, that is: (1) Diameter $11 \mathrm{~cm}$, pipe thickness $3 \mathrm{~mm}$, length $60 \mathrm{~cm}$; (2) Diameter $20 \mathrm{~cm}$, pipe thickness $4 \mathrm{~mm}$, length $25 \mathrm{~cm}$. It fetched soil from the field, and original soil should avoid been disturbed during the whole process.

The original soil was then dried in nature air, took impregnant to marinate the soil columniation next, it must be slowly and separately immitted, to the greatest extent to be immerged into soil macropore. When there was $0.5 \mathrm{~cm}$ impregnant higher than soil surface in the pipe, just stopped immerging and placed until impregnant completely solidified. The last step was skived the soil with electromotion thin grinding wheel, obtained many real multicolor surface every other $5 \mathrm{~mm}$ by scanner 。

\subsection{Obtain digital images}

Used the large-scale image disposal software ImageSys and Photoshop to pick-up macropore area (based on the precision of this experimental investigation and data processing level, considered the hole that larger than $100 \mu \mathrm{m}$ as macropore). The final data were following series macroporous degrees:(1) $600 \mathrm{~mm}$ underground depth, diameter scope $104 \mathrm{~mm}$, every other $5 \mathrm{~mm}$ interval ; (2) $230 \mathrm{~mm}$ underground depth, diameter scope $25 \mathrm{~mm}$ 、 $40 \mathrm{~mm} 、 60 \mathrm{~mm} 、 80 \mathrm{~mm} 、 100 \mathrm{~mm} 、 125 \mathrm{~mm} 、 150 \mathrm{~mm} 、 175 \mathrm{~mm}$, every other $10 \mathrm{~mm}$ interval. 


\section{RESULTS AND ANALYSIS}

\subsection{Semi-variance analysis}

\subsubsection{Model choice}

Semi-variance function was the foundation of spatial variability explaining by geostatistical theory. It was usually expressed by experimental semi-variogram. These curves can be fitted by curve equation. These curve equations were called of semi-variance function. There were spherical model, Gaussian model, the index model and the linear model. The theoretical model of choice depended on the specific cases. According to the studies of predecessors, theoretical variogram model of soil properties were generally the spherical model of transition (Masaru Hoshiya, 1995; Gotway C A. R B Ferguson,1996). When selecting the semi-variance model, first of all, used the equation (1) to calculate $\gamma(h)$ scatter plot, then fitted the curves with spherical model, that was :

$$
\gamma(h)=\left\{\begin{array}{lc}
0 & h=0 \\
C_{0}+C\left(\frac{3}{2} \frac{h}{a}-\frac{1}{2} \frac{h^{3}}{a^{3}}\right) & 0<h \leq a \\
C_{0}+C & h>a
\end{array}\right.
$$

Where $C_{0}$ was the value for the block, meaned semi-variance when distance approached zero. It was the variability caused by random factors such as experimental error; $C$ was structure variance. It was the variability caused by non-human factors such as soil parent material, terrain and so on.; $a$ was the related socpe of the observation points.

\subsubsection{Test of model precision}

In order to make sure the theoretical models of semi-variance really describe the law of the changes, it must do the optimal test. The tests were usually cross-examination, the estimated variance test and $I$ value test. The cross-examination was the theoretical variogram model of "the square of decrease between kriging estimates and measured value was minimum". The estimated variance test was the method which do the test through the ratio of the practical variance and theoretical estimated variance. If the theoretical variation function properly fitted, then $\overline{\left(z^{*}-z\right)^{2} /\left(s^{*}\right)^{2}}$ should be fluctuated around 1. I value test integrated the above two indicators into a unified theory (Hou Jingru et at., 1982), formula was as follows: 
Theory

$$
\left.I=\overline{\left(z^{*}-z\right)^{2}} \times|P \times| 1-\frac{1}{\left[\left(z^{*}-z\right) / s^{*}\right]^{2}} \mid+(1-P)\right]
$$

Where $P$ was parameters for the empirical. When $0 \leq \overline{\left(z^{*}-z\right)^{2}}<100, P$ was 0.1. When $100 \leq \overline{\left(z^{*}-z\right)^{2}}, P$ was 0.2 . The smaller $I$ value, the higher fitted precision of variation function model. Three methods were used to test the model. The results were shown in Table1 and Table2. The corresponding map of semi-variogram was as Fig. 1.

In order to quantificationally describe how scale change impact model precision, change rate of model precision was introduced, that was:

$$
\mathrm{k}(\% 0)=\left|\left(I_{2}-I_{1}\right)\right| / \delta * 1000
$$

The results were shown in Fig .2 and Fig.4.

Table 1. Theoretical model and model testing parameters of macroporous degree under the

\begin{tabular}{|c|c|c|c|c|c|c|c|c|}
\hline $\begin{array}{l}\text { Minimum Step } \\
(\mathrm{mm})\end{array}$ & $\begin{array}{l}C_{0} \\
(\%)\end{array}$ & $\begin{array}{c}C \\
(\%)\end{array}$ & $\begin{array}{c}\frac{C_{0}}{\left(C+C_{0}\right)} \\
(\%)\end{array}$ & $\begin{array}{l}\text { Variable } a \\
\quad(\mathrm{~mm})\end{array}$ & $\overline{\left(z^{*}-z\right)^{2}}$ & $\overline{\left(\left(z^{*}-z\right) / s^{*}\right)^{*}}$ & $P$ & $I$ \\
\hline 5 & 0.23 & 0.43 & 34.8 & 201.6 & 0.0027 & 0.97 & 0.1 & 0.0025 \\
\hline 10 & 0.29 & 0.47 & 38.2 & 199.8 & 0.0041 & 1.05 & 0.1 & 0.0037 \\
\hline 15 & 0.40 & 0.35 & 53.3 & 202.7 & 0.0052 & 1.00 & 0.1 & 0.0047 \\
\hline 20 & 0.42 & 0.48 & 46.7 & 199.1 & 0.0025 & 1.09 & 0.1 & 0.0048 \\
\hline 25 & 0.59 & 0.47 & 55.7 & 210.8 & 0.0038 & 0.99 & 0.1 & 0.0058 \\
\hline 30 & 0.55 & 0.55 & 50.0 & 231.6 & 0.0042 & 1.02 & 0.1 & 0.0055 \\
\hline
\end{tabular}
condition of the differernt minimum step
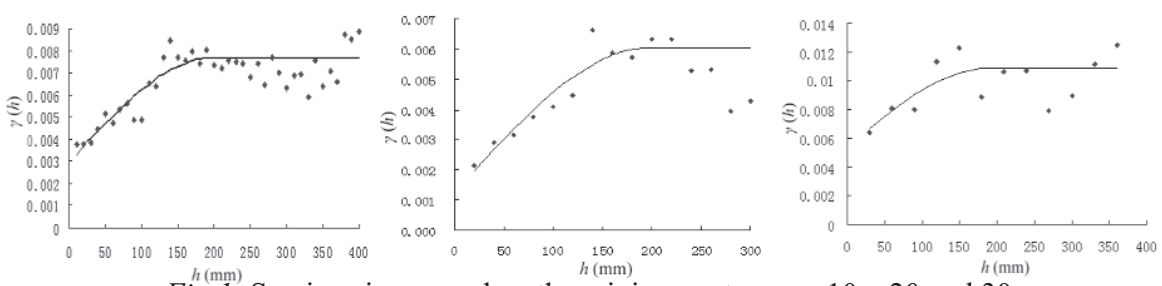

Fig. 1: Semi-variogram when the minimum step was $10 、 20$ and $30 \mathrm{~mm}$

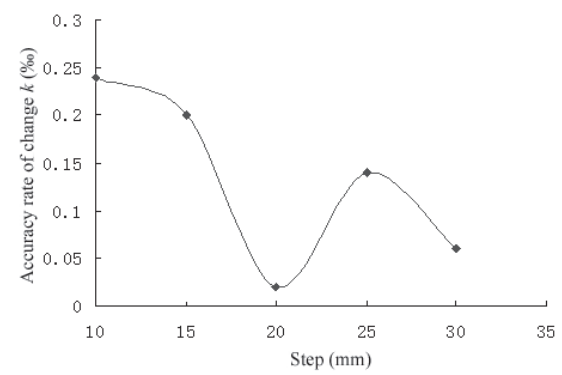

Fig.2 : Relationship between change rate of model accuracy and step 
Table 2. Theoretical model and model testing parameters s of macroporous degree under the condition of differeent sampling diameter

\begin{tabular}{|c|c|c|c|c|c|c|c|c|}
\hline $\begin{array}{l}\text { Sampling } \\
\text { Diameter } \\
(\mathrm{Mm})\end{array}$ & $\begin{array}{c}C_{0} \\
(\%)\end{array}$ & $\begin{array}{c}C \\
(\%)\end{array}$ & $\begin{array}{c}\frac{C_{0}}{\left(C+C_{0}\right)} \\
(\%)\end{array}$ & $\begin{array}{c}\text { Variable } \\
a(\mathrm{~mm})\end{array}$ & $\overline{\left(z^{*}-z\right)^{2}}$ & $\overline{\left(\left(z^{*}-z\right) / s^{*}\right)^{*}}$ & $P$ & $I$ \\
\hline 25 & 2.12 & 0.66 & 76.3 & 47.9 & 0.0268 & 0.96 & 0.1 & 0.0243 \\
\hline 40 & 1.36 & 0.83 & 62.1 & 32.5 & 0.0237 & 0.94 & 0.1 & 0.0296 \\
\hline 60 & 1.55 & 0.67 & 69.8 & 61.8 & 0.0197 & 1.02 & 0.1 & 0.0159 \\
\hline 80 & 0.59 & 1.86 & 24.1 & 94.05 & 0.0128 & 1.19 & 0.1 & 0.0117 \\
\hline 100 & 0.11 & 1.96 & 5.31 & 97.70 & 0.0084 & 1.28 & 0.1 & 0.008 \\
\hline 125 & 0.28 & 3.95 & 6.62 & 93.24 & 0.0146 & 1.06 & 0.1 & 0.0132 \\
\hline 150 & 0.10 & 2.41 & 3.98 & 89.44 & 0.0099 & 1.13 & 0.1 & 0.0093 \\
\hline 175 & 0.02 & 1.54 & 1.28 & 97.92 & 0.0047 & 1.15 & 0.1 & 0.0044 \\
\hline
\end{tabular}
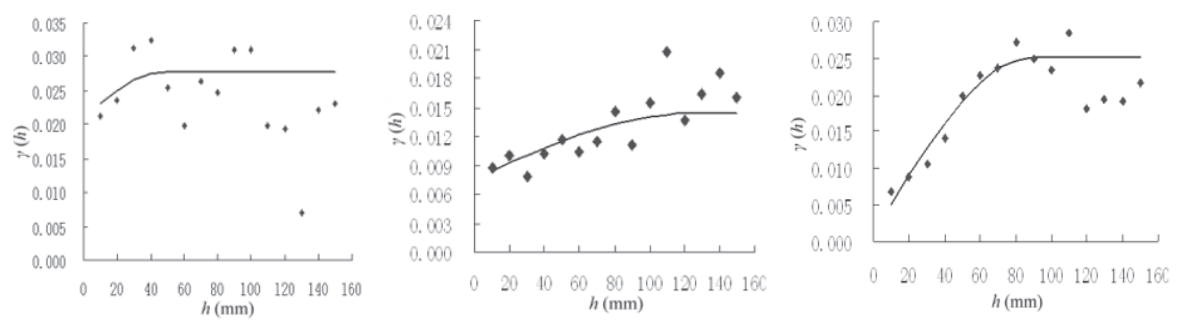

Fig. 3: Semi-variogram when the sampling diameter was 25、60、150mm

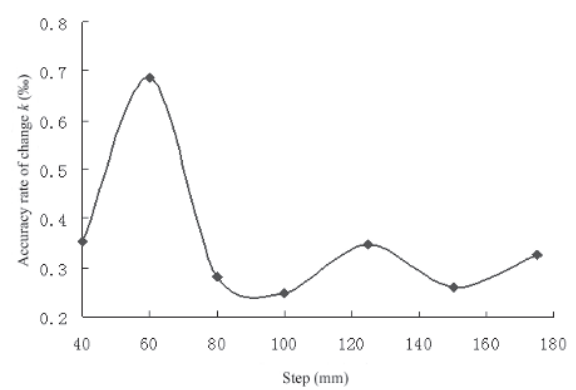

Fig.4: Rrelationship between change rate of model accuracy and sampling diameter

\subsection{Reasonable scale analysis}

From Table 1. and Fig.1 4, it can be found that the precision change rate gradually decreased between $10 \mathrm{~mm}$ and $20 \mathrm{~mm}$ step. The precision varied larger with these step. When the step achived $20 \mathrm{~mm}$, the rate of model precision achieved smallest. And then it had tend to stabilize ups and downs. $20 \mathrm{~mm}$ could be considered the critical step. But $\overline{\left(z^{*}-z\right)^{2}}$ and $I$ increased along with the minimum step increased. For example $I$ value increased from 0.0051 to 0.0025 . It showed that sampling interval can not be too large. Because even if sample spacing increased, the workload reduced, and at the 
Theory

same time it caused academic model would not primely describe variable characteristics and special structure of macropore degree in soil. And the accuracy of estimates and simulation would also reduce.

Table 2. and Fig.5 8 said that when the sampling diameter was between 40 $\mathrm{mm}$ and $80 \mathrm{~mm}$, model precision varied from $0.28 \%$ to $0.685 \%$, changed distinctly. Model precision change rate reached the smallest between $80 \mathrm{~mm}$ and $100 \mathrm{~mm}$. In the context, the model precision achieved the highest point of local and then changed in the steady state. $I$ value slightly reduced with the sampling increaced, concretely minished from 0.00243 to $0.0044(<10 \%)$. The larger the sampling diameter, the higher simulation accuracy of calculation and of variogram were. The sampling diameter went bigger, it could reflect the nature of the porosity more. But this would spend a significant amount of manpower, material. It said that $80 \sim 100 \mathrm{~mm}$ could be taken for reasonable sample diameter.

\section{CONCLUSION}

This paper took geostatistical theory into microcosmic domain to research macropore distributing, analysis the spatial structural characteristic, broadened the application of goestatistical theory. It had two conclusions as follows:

(1) Used digital image analysis technology to visually describe the number of the soil macropore, size and other characteristics. It said that the macropore degree had roughly the same trend in different soil column. Max value basically concentrated lied underground $12 \mathrm{~cm}$ to $18 \mathrm{~cm}$, that was cultivation layer. The maximum of macropore area changed little. But the maximum of macropore perimeter fluctuated in the apparent trend. This showed in the vertical section, the difference of macropore spatial distribution structure was different.

(2) Used geostatistical theory to research the spatial structure of the macropore of soil. Analysised the spatial structure of macropore on both vertical and horizontal directions. Through the parameters such as $C_{0}, C$, Variable, $I$, model precision change rate $k$ and so on, it showed that $20 \mathrm{~mm}$ was reasonable sampling interval in the vertical depth. $80 \sim 100 \mathrm{~mm}$ was the economically reasonable sampling diameter in the level. This provided instruction for soil moisture, solute movement regulation and setting up exact predictive model for cropland moisture. 


\section{ACKNOWLEDGEMENTS}

This research was funded by the Program of State Key Laboratory of Hydrology-Water Resources and Hydraulic Foundation, Hohai Universty( accession number 2006zd04).

\section{REFERENCES}

Gotway C A. R B Ferguson. G H Hergert and T A Peterson. Comparison of kriging and inverse-distance methods for soil parameters. Soil Sci, 1996 (60) : 1237 1247

Hou Jingru, Guo Guangyu. Forecast of deposit Statistics and theory and application of Geostatistical theory [M]. Beijing: metallurgy and industry publishing company, 1993, $6 \sim 8$

Hou Jingru, Huang Jingxian.Theory and method of geostatistics [M]. Beijing: Geological publishing company, 1982

Hou Jingru, Hung Jingxian. Geostatistical theory and its application in calculation of mine rescourses [M]. Beijing: Geological publishing company, 1982

Li Weiping, Shi Haibin, Huo Zailin. Spatial structure of the height and diameter of sunflower stem [J]. Transactions of The Chinese Society of Agricultural Engineering, 2004, 20(4): $30-33$

Li Zizhong, Gong Yuanshi. Spatial variability of soil water content and electrical conductivity in field for different sampling scales and their nested models [J]. Plant Natrition and Fertilizen Science, 2001, 7(3): 255-261

Masaru Hoshiya. Kriging and Conditional simulation of Gaussian Field. Journal of Engineering Mechanics, 1995, 121 (2)

Shi Haibin, Chen Yaxin. Combination structure model of soil moisture spatial variability and regional information estimation[J]. Journal of hydraulic engineering, 1994, (7): 70-77

Wang Renduo, Hu Guangdao, Linear. Geostatistics. Beijing: Geological publishing company, 1988

Westerna A W, Bloschl G. On the spatial scaling of soil moisture [J]. Journal of Hydrology, 1999, (17): 203-224 